\title{
Preparation and Activation of Sarulla Natural Zeolites as an Adsorbent in Purification Process of Crude Palm Oil
}

\author{
HAFNI INDRIATI NASUTION ${ }^{1}$, MOONDRA ZUBIR ${ }^{1 *}$, JASMIDI ${ }^{1}$, MAHARANI ${ }^{1}$, \\ AHMAD GAZALI SOFWAN ${ }^{2}$ and JUNIFA LAYLA SIHOMBING' ${ }^{1}$
}

${ }^{1}$ Department of Chemistry, Faculty of Mathematics and Natural Science, State University of Medan,
Jl.Willem Iskandar, Ps V, Medan Estate, Medan, North Sumatera 20221, Indonesia.
${ }^{2}$ Indonesian Oil Palm Research Institute, Medan, North Sumatera, Indonesia.
${ }^{*}$ Corresponding author E-mail: moondrazubir@ @unimed.ac.id

http://dx.doi.org/10.13005/ojc/350228

(Received: December 26, 2018; Accepted: March 30, 2019)

\begin{abstract}
The effect of Sarulla zeolite in Crude palm oil (CPO) purification was analyzed in zeolite weight and contact time variation on the influence of Free Fatty Acid, Saponification Value, Carotene, Vitamin-E, and Squalene content. This purification process induce increasing of saponification value from $272.41 \mathrm{mg} \mathrm{KOH} / \mathrm{g}$ to $316.42 \mathrm{mg} \mathrm{KOH} / \mathrm{g}$ at $20 \mathrm{~g}$ of zeolite and contact time for 30 minutes. On the other hand, this purification process reduced of Free Fatty Acid (FFA) content from $2.86 \%$ to $1.6 \%$ and vitamin E content from $907.79 \mathrm{ppm}$ to $376.54 \mathrm{ppm}$ after were adsorbed for 90 min with 30 $\mathrm{g}$ of zeolite used. Fatty acid composition analysis on CPO not significant changes in which is palmitic acid increased or decreased by about $1 \%$ under various conditions of zeolite use and contact time on the adsorption process. Sarulla natural zeolite can be used for CPO purification without affect theirs main content.
\end{abstract}

Keywords: Crude Palm Oil, Purification, Natural Zeolite, Adsorption.

\section{INTRODUCTION}

Indonesia has a variety of natural resources which potential to be developed into various foodstuffs. Oil palm is a plant that grows well in tropical climates with rainfall around $2000 \mathrm{~mm} /$ year and temperature range $22-32^{\circ} \mathrm{C}$. Currently, 11 million hectares of oil palm plantations in Indonesia have produced crude palm oil with a production capacity of 31.10 million tons per year and it is the largest of palm oil production in the world. ${ }^{1} \mathrm{CPO}$ (Crude palm oil) is a crude oil obtained by extraction of palm flesh and usually still contains dissolved impurities and not dissolved in oil. This impurities known as gum or resin contain of phosphatides, proteins, hydrocarbons, carbohydrates, water, resins, free fatty acids (FFA), tocopherols, pigments and other compounds. CPO is also known rich with natural dyes as $\alpha$-carotene, $\beta$-carotene, xanthophyll, chlorophyll and anthocyanin. These dyes cause oil colour become yellow, yellowbrownish, greenish and reddish. ${ }^{2}$

This is an Open Access article licensed under a Creative Commons license: Attribution 4.0 International (CC- BY). Published by Oriental Scientific Publishing Company @ 2018 
Excessive dye content on CPO will degrade the quality and affect the physical appearance, taste, odor and oil storage time, so it must be removed by physical or chemical separation process. The process of purification is one of strategic to reduce or eliminate dyestuffs in crude oil (CPO), whether dissolved or dispersed. The color of the crude oil can be derived from the color of the congenital oils or the colors arise during the processing. One of the alternative solutions to reducing carotene or dyestuff content in CPO is purification by adsorption method. This process would absorb carotene in CPO by using adsorbent material as clay and activated carbon. ${ }^{3}$

Beside activated carbon, ${ }^{4}$ zeolite also can use as an absorbent but not many research have used zeolite as an adsorbent for CPO purification. ${ }^{5}$ This ability due to the presence of $\mathrm{SiO}_{2}$ and $\mathrm{AlO}_{2}$ on the surface of the adsorbent to adsorb the $\beta$ carotene in palm oil. ${ }^{6}$ Indonesia has a large reserve of natural zeolite that spread around 50 locations, especially around volcano area like in East Java, Central Java, West Java, Borneo, Nusa southeast, Maluku to Sumatra which potentially have deposits of 16.6 million tons. ${ }^{1}$

In this research, natural zeolite from Sarulla village, Pahae Jae district in North Sumatera was used as an adsorbent in CPO purification to improve the quality of palm oil. This purification was performed by mixing CPO with variation of zeolite amount and variation of adsorption time. CPO feed and after purification were determined of Free Fatty Acid (FFA) content, Saponification Value (SV), carotene content, vitamin $\mathrm{E}_{\text {content }}{ }^{7}$ and squalene content. ${ }^{8}$ Fatty acid composition was observed to confirm this purification process will not change the quality of palm oil. The utilization of natural zeolite as an adsorbent for palm oil was expected to promote this natural zeolite on produce more pure and high quality of CPO.

\section{MATERIALS AND METHODS}

CPO feed in this experiment was taken from Adolina, one of palm oil Company in North Sumatera. Sarulla zeolite, n-hexane, $\mathrm{HCl} 0.5 \mathrm{~N}, \mathrm{HCl}$ $1 \mathrm{~N}$, Oxalic Acid $\left(\mathrm{H}_{2} \mathrm{C}_{2} \mathrm{O}_{4}\right)$, Phenolphthalein Indicator, Sodium Tetraborat $\left(\mathrm{Na}_{2} \mathrm{~B}_{4} \mathrm{O}_{7} \cdot 10 \mathrm{H}_{2} \mathrm{O}\right)$, Ethyl Alcohol, $\mathrm{KOH} 0,01 \mathrm{~N}, \mathrm{KOH}$ Alcoholic $0.5 \mathrm{~N}$, Vitamin C 0,1\%, $\mathrm{KOH} 50 \%$, Ethanol $40 \%, \mathrm{NaOH}$ Methanolic 0,5 N,
$\mathrm{BF}$, Methanol, $\mathrm{NaCl}$ saturated and aquadest were used in this experiment.

\section{Preparation of Sarulla Zeolite}

Natural zeolite was collected from Sarulla, Tapanuli Utara area and grilled with mortar and pestle, sieved with 100 mesh size to obtain zeolite grain size less than 100 mesh. Then zeolite was washed with aquadest and dried in oven at $110^{\circ} \mathrm{C}$ for 3 hours. Prepared zeolite were kept in desiccators and measured of initial crystal structure by XRD.

\section{Activation of Sarulla Zeolite}

$100 \mathrm{~g}$ prepared zeolite was mixed with $200 \mathrm{~mL}$ of $\mathrm{HCl} 1 \mathrm{~N}$ and stirred at $150 \mathrm{rpm}$ for 3 hours. The zeolite was filtered by using filter paper whatman No.42 and rinsed with aquadest until neutral $\mathrm{pH}$ and dried it at $110^{\circ} \mathrm{C}$ for 3 hours. This process was continued with the calcination process at $300^{\circ} \mathrm{C}$ for $2 \mathrm{~h}$ to obtain activated natural zeolite. This activated zeolite was characterized with XRD analysis.

\section{Purification of CPO by Sarulla Zeolite}

Purification of CPO by using activated Sarulla zeolite was measured by weighing each $100 \mathrm{~g}$ of CPO, and put into a $250 \mathrm{~mL}$ beaker glass. $10 \mathrm{~g}, 20 \mathrm{~g}$, and $30 \mathrm{~g}$ activated Sarulla zeolite was added and heated at $90^{\circ} \mathrm{C}$ by stirring for 30,60 , and 90 minutes. CPO after adsorption was filtered and characterized as below parameter.

\section{Characterization}

Change of Zeolite structure after activation was measured by X-ray Diffractometer, XRD Shimadzu 6100. Carotene content was measured by UV-Visible Spectrophotometer (UV-Vis) and squalene content was determined by Gas Chromatography Mass Spectrometry (GC-MS). High Performance Liquid Chromatography (HPLC) was used to measure Vitamin E content and Gas Chromatography (GC) to determine composition change of fatty acid after purification.

\section{RESULTS AND DISCUSSION}

Activation by using $\mathrm{HCl}$ aims to dissolve acid-soluble impurities such as alkaline metal oxide compounds. Activation with acid causes de-cationation to increase zeolite surface area with reduce the impurities which cover the pores of zeolite. Using low concentrations of $\mathrm{HCl}$ in the 
zeolite activation process to avoid the structural damage. Zeolite was immersed in $\mathrm{HCl}$, then filtered with filter paper and washed with aquadest until neutral $\mathrm{pH}$ removed $\mathrm{Cl}^{-}$in the activated zeolite cavity. To confirm it was investigated with addition of $\mathrm{AgNO}_{3}$. No sedimentation after the addition of $\mathrm{AgNO}_{3}$ indicates zeolite is completely free of $\mathrm{Cl}^{-}$. Then it was calcined to evaporate the trapped water in zeolite pores, burning the organic compounds contained in the zeolite and it induce the zeolite surface area increases, and to obtain a good form of crystallinity. Fig. 1 shows the XRD pattern of Sarulla natural zeolite from the preparation process and the activation process.

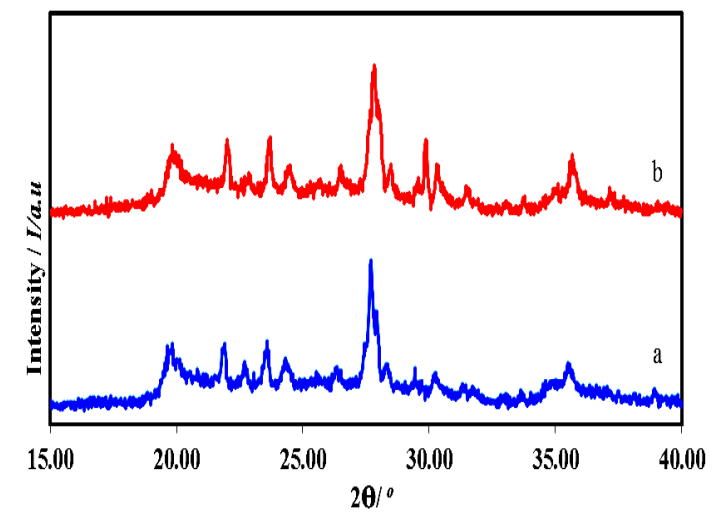

Fig. 1. XRD pattern of Sarulla Zeolite (a) and Sarulla Zeolite after Activation (b)

Prepared Sarulla Zeolite shows high intensity around $27.70^{\circ}, 23.57^{\circ}, 19.81^{\circ}, 22.67^{\circ}$, and $35.50^{\circ}$. On the other hand, activated Sarulla zeolite was observed a high intensity at $27,83^{\circ}, 23,69^{\circ}$, $29,86^{\circ}, 19,84^{\circ}$, and $35,66^{\circ}$. Some peaks of decreased intensity indicates loss of impurities which caused by activation process. XRD pattern also confirm that activation process of Sarulla zeolite is not destructive and does not alter the zeolite structure characterized by no significant change in XRD peaks. The activation process was succeed to remove impurities contained in the Sarulla natural zeolite. According to EXPO 2014 analysis, ${ }^{9}$ the same crystalline system of the Sarulla natural zeolites after preparation and after activation form a triclinic crystal system but the volume of crystals system after activation was greater than after preparation. Its supported by XRD data that the activation of Sarulla natural zeolite was successfully remove the impurities.

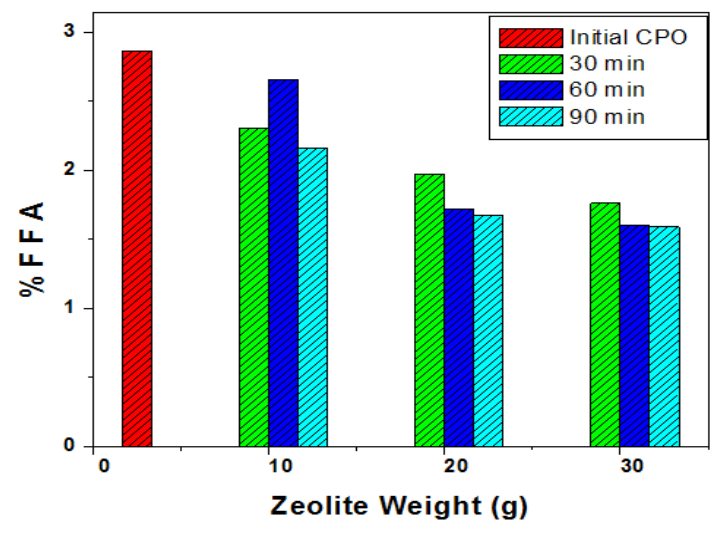

Fig. 2. Weight dependence with contact time of FFA content of Crude palm oil

Characteristics of the palm oil quality was influenced by its free fatty acid content (Fig. 2). For calculations, the FFA content of palm oil is considered as Palmitic Acid (molecular weight 256) and high levels of FFA indicate poor quality of oil. FFA was measured by volumetric titration method where analysis of the amount of free fatty acid of a sample equivalent to the amount of base $(\mathrm{KOH})$ added in the titration, indicated by the color change. ${ }^{10}$ Free Fatty Acid (FFA) on CPO before the purification process is $2.86 \%$. After purification with Sarulla zeolite, the optimum FFA value was decreased to $1.60 \%$ at $30 \mathrm{~g}$ Sarulla zeolite and 90 min contact time. It indicate the adsorbent weight and contact time in $\mathrm{CPO}$ refining process induce to the decrease of FFA content. By increasing of Sarulla zeolite weight and contact time will effective to purify of CPO which significant influence on the quality of CPO. Reducing of FFA value is significance around $44.1 \%$, higher than purification process of Zeolite from Klaten which reduced of FFA value as $17.5 \% .^{15}$

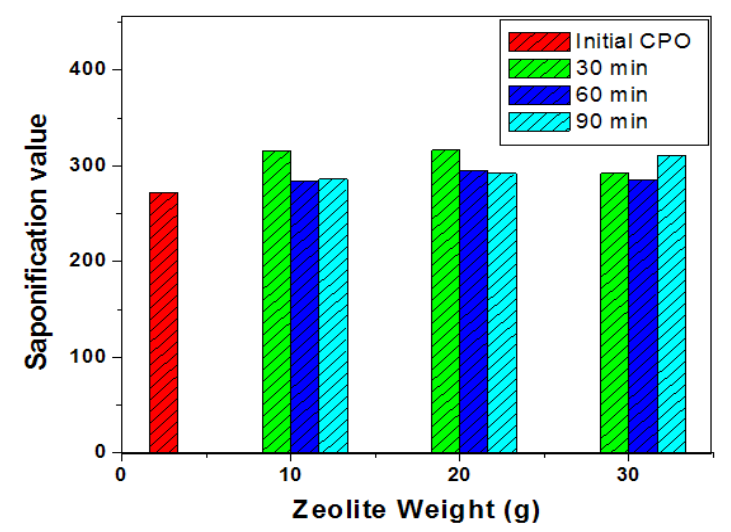

Fig. 3. Weight dependence with contact time of Saponification Value of Crude palm oil 
Saponification Value is the amount of $(\mathrm{mg})$ $\mathrm{KOH}$ required to soap one gram oil or fat and alcohol presence in $\mathrm{KOH}$ to dissolve the fatty acids from the hydrolysis and facilitate the reaction with the base to form soap. ${ }^{11}$ The greater of saponification value induce the lower fatty acids and better oil quality, otherwise if the saponification value is low, it increase the fatty acid and quality of CPO was decreased. The saponification value of initial CPO is $272.41 \mathrm{mg} \mathrm{KOH} / \mathrm{g}$, but after added of adsorbent and longer contact time observed the increasing of saponification value. The smallest Saponification Value after the addition of adsorbent was obtained at $10 \mathrm{~g}$ zeolite as $283.91 \mathrm{mg} \mathrm{KOH} / \mathrm{g}$ with contact time $60 \mathrm{~min}$ and the highest saponification value at zeolite mass $20 \mathrm{~g}$ and 30 increase the saponification value to produce more quality of oil palm.

The main carotenoids of palm oil are alpha-carotene and beta-carotene; together contain $80 \%$ of the total carotenoids in palm oil with $36.4 \%$ alpha-carotene and $54.4 \%$ beta-carotene. ${ }^{9} \mathrm{CPO}$ has a high carotene content around 500-700 ppm. Beside as a color given, carotene also acts as an antioxidant in the body and serves as a precursor of vitamin $A$ especially for $\beta$-carotene formation. ${ }^{12}$ Codex Alimentarius Commission (2003) used as a reference in international trade specifies that the requirement of carotene content ranges of $\mathrm{CPO}$ around 500-2000 ppm. Fig. 4 shows the highest carotene content was possessed by the initial CPO sample with a carotene content is $460 \mathrm{ppm}$ and the lowest is a variation of zeolite mass of $30 \mathrm{~g}$ and contact time of $60 \mathrm{~min}$ and $20 \mathrm{~g}$ of zeolite mass with contact time of $90 \mathrm{~min}$ as $5 \mathrm{ppm}$ carotene content. The longer stirring time on the zeolite and increase of zeolite amount to purify the CPO will reduce carotene content. The differences of carotene content and drastic decrease after purification were caused by several factors, as palm oil varieties and maturity level of palm fruit. It suggest the purified CPO will lose its carotene content, indicates the purified CPO was not recommended for food and beverage consumption due to very low carotene content, but can be used in other industries such as cosmetics and medicine. ${ }^{7,13}$

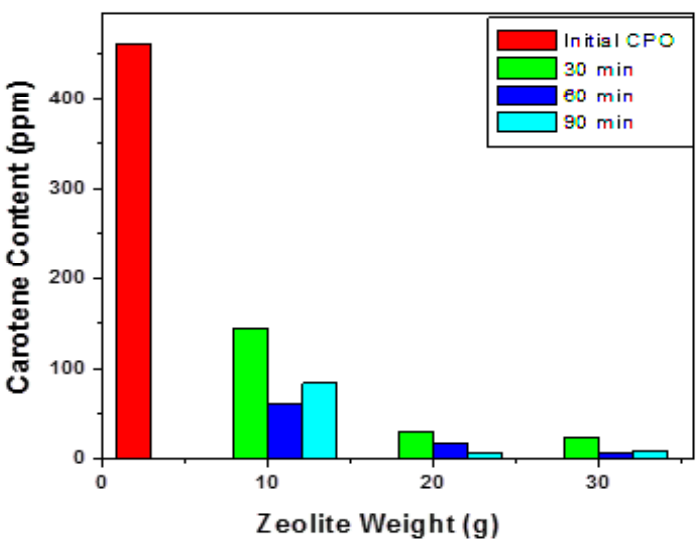

Fig. 4. Weight dependence with contact time to Carotene content of Crude palm oil

Purified CPO was determined of reduction vitamin $\mathrm{E}$ content as $376.54 \mathrm{ppm}$ in the $30 \mathrm{~g}$ zeolite and 90 min contact time compared to initial CPO is 907.79 ppm (Fig. 5). It suggest by increasing zeolites weight will effect more vitamin E adsorbed by zeolites and produce lower levels of vitamin E. The highest vitamin $\mathrm{E}$ content of purified CPO was measured in $20 \mathrm{~g}$ Sarulla zeolite and a contact time of $30 \mathrm{~min}$ is $808.01 \mathrm{ppm}$. The content of d-tocotrienol and a-tocopherol levels in CPO induce the high vitamin E produced, and g-tocotrienol and a-tocotrienol level of purified CPO is lower than the initial CPO. ${ }^{14}$

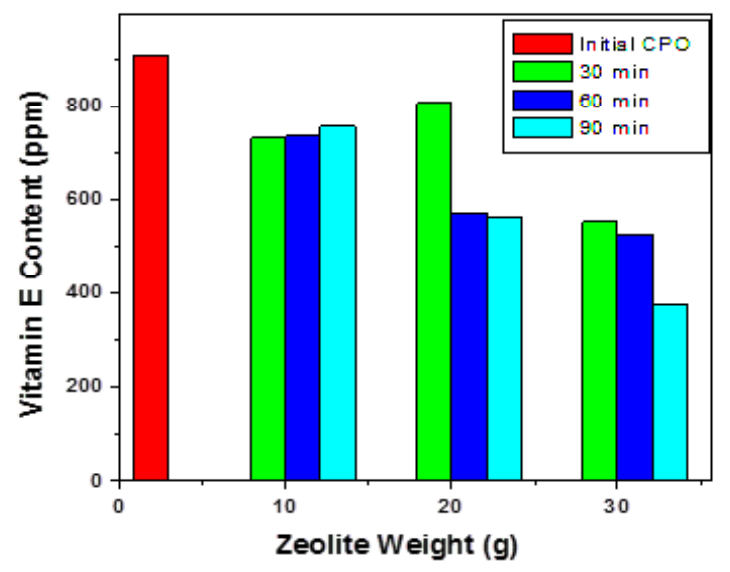

Fig. 5. Weight dependence with contact time to Vitamin E content of Crude palm oil

The purified crude palm oil had elevated levels of squalene content as $247.51 \mathrm{ppm}$ compared than the initial sample is $162.99 \mathrm{ppm}$. After purification with Sarulla natural zeolite the level of squalene increase, but on the addition of $20 \mathrm{~g}$ zeolite 
with stirring time of 90 min squalene level decreased to 244.68 ppm, although squalene level decreased in the variation, purification CPO remains better because the squalene content is higher than intial CPO. In this study the analysis results of squalene levels increased to $65 \%$ where 60 min contact time and used $20 \mathrm{~g}$ zeolite. Its suppose that purified CPO with high squalene content is more suitable to use as a cosmetic ingredient. ${ }^{8}$

The analysis of fatty acid composition aims to determine the percentage of saturated fatty acid (C: 12-C: 18) and unsaturated (C: 18.1-C: 18.3) contained in Crude Palm Oil. Initial CPO was determined of oleic acid content (C18: 1) about $38 \%$ while CPO adsorption use $30 \mathrm{~g}$ and $90 \mathrm{~min}$ contact time, oleic acid decreased to $37 \%$ and 30 $\mathrm{g}$ with 60 min contact time, oleic acid increased to $39 \%$. For palmitic acid content at initial CPO only $46 \%$ but purified CPO with $20 \mathrm{~g}$ and 60 min contact time decreased to $44 \%$ as palm oil with lowest palmitate content, while on purified CPO with variation $20 \mathrm{~g} 30 \mathrm{~min}$, palmitic acid content increased to $47 \%$.

Table 1: Fatty Acid composition of purified Crude palm oil

\begin{tabular}{|c|c|c|c|c|c|c|c|c|c|c|}
\hline \multirow{2}{*}{$\begin{array}{c}\text { Fatty Acid } \\
\text { Content in CPO }\end{array}$} & \multicolumn{10}{|c|}{ Measurement Parameter zeolite weight (g), contact time (min) } \\
\hline & Initial & 10,30 & 10,60 & 10,90 & 20,30 & 20,60 & 20,90 & 30,30 & 30,60 & 30,90 \\
\hline Laurat Acid & 0,16 & 0,16 & 0,17 & 0,16 & 0,34 & 0,15 & 0,15 & 0,18 & 0,19 & 0,66 \\
\hline Miristat Acid & 0,80 & 0,77 & 0,80 & 0,81 & 0,89 & 0,71 & 0,76 & 0,80 & 0,74 & 1,02 \\
\hline Palmitat Acid & 46,27 & 45,24 & 46,21 & 45,65 & 47,54 & 44,30 & 45,83 & 45,24 & 44,34 & 46,20 \\
\hline Palmitoleat Acid & 0,11 & 0,11 & 0,11 & 0,11 & 0,12 & 0,12 & 0,11 & 0,12 & 0,11 & 0,23 \\
\hline Stearat Acid & 3,73 & 3,83 & 3,81 & 3,88 & 3,83 & 3,66 & 3,87 & 3,81 & 3,99 & 3,90 \\
\hline Oleat Acid & 38,09 & 38,84 & 37,99 & 38,40 & 38,00 & 39,81 & 38,30 & 38,47 & 39,82 & 37,34 \\
\hline Linoleat Acid & 10,28 & 10,48 & 10,33 & 10,42 & 10,22 & 10,71 & 10,39 & 10,80 & 10,21 & 10,25 \\
\hline Linolenat Acid & 0,17 & 0,18 & 0,18 & 0,19 & 0,18 & 0,19 & 0,18 & 0,19 & 0,19 & 0,19 \\
\hline Arachidat Acid & 0,28 & 0,29 & 0,29 & 0,29 & 0,23 & 0,27 & 0,29 & 0,29 & 0,31 & 0,29 \\
\hline Eicosenoat Acid & 0,08 & 0,09 & 0,08 & 0,09 & 0,09 & 0,08 & 0,09 & 0,08 & 0,10 & 0,09 \\
\hline
\end{tabular}

\section{CONCLUSION}

Purification of CPO by using Sarulla natural zeolite successful in decreasing free fatty acid content from $2,86 \%$ to $1.6 \%$, increasing saponification value from 272.41 to $316,42 \mathrm{mg} \mathrm{KOH} / \mathrm{g}$ and also increase of squalene from $162.99 \%$ to 247,5 . However, even this purification induce decrease of carotene levels to 5 ppm and vitamin-E content to 376.54 ppm, but CPO purified by Sarulla natural zeolite is suitable for the manufacture of drugs and cosmetics. This purification process not significant effect to composition of fatty acids which palmitic acid has a slight increase of $1 \%$ and a decrease of $1 \%$ in some experimental variation conditions. It could be concluded, Sarulla natural zeolite is suitable for CPO purification.

\section{ACKNOWLEDGMENT}

This research did not receive any specific grant from funding agencies in the public, commercial, or not-for-profit sectors.

\section{Conflict of interest}

All authors declare no conflicts of interest in this paper.

\section{REFERENCES}

1. Petrenko; Julia P; Stephanie S., International Council on Clean Transportation., 2016.

2. D.J. Osborne; J.Henderson. Journal endevour., 2000, 24, 63-68.

3. Simone M.S; Roberta C; Roland V; Christian S; WimDe G; Antonio J.A.M. Journal of Food Engineering., 2013, 341-349.

4. Agus K; Moondra Z; Jasmidi; Albinus S. Asian
Journal of Chemistry, 2018, 30, 5, 944-946.

5. Asalil M; Gede W; Mukhammad F.N.; Miftakhul F. Indonesian Journal of Chemistry., 2014, 14, 2, 138-142.

6. Maria U; Sri R; Pudji H; Purnama D. AIP Conference Proceedings., 2016, 1755, 130016.

7. Chu B.S.; Quek S.Y.; Baharin B.S. Food Chemistry., 2003, 80(3), 295-302. 
8. Derek M.;Armelle P.; Lance K.; Loren P.Cosmetics \& Toiletries Magazine., 2014, 129(6), 2012.

9. Altomare, A.; Cuocci, C.; Giacovazzo, C.; Moliterni, A.; Rizzi, R.; Corriero, N.; Falcicchio. J. Appl. Cryst., 2013, 46, 1231-1235.

10. Mahesar S. A.;. Sherazi S. T. H ; Khaskheli A.R,; Aftab A.K.; Kandhro; Sirajuddin. Analitycal method., 2014, 6, 14-18.

11. Mustapha Abdulrahman. IOSR Journal of Applied Chemistry (IOSR-JAC)., 2016, 9(1) 2278-5736.
12. Latip R. A.; Baharin B. S.; Che Man Y. B.; Abdul Rahman R., Journal of the American Oil Chemists' Society., 2001, 78(1), 83-87.

13. Ooi C. K.; Choo Y. M.; Yap S. C.; Basiron Y.; Ong A. S. H., Journal of the American Oil Chemists' Society., 1994, 71(4), 1994, 423-426.

14. Ab Gapor,M.T. Palm Oil Development, 1990, 12, 25-27

15. Monika L.; Putranti T.A.; Wirawan S.K.; I Made Bendiyasa, IOP Conf. Series: Materials Science and Engineering., 2018, 299-304. 